\title{
The past, present, and future of population geography in China:
}

\section{Progress, challenges and opportunities}

\author{
FENG Zhiming ${ }^{1,2,3}$, LI Fangzhou ${ }^{1,4}$, 'YANG Yanzhao ${ }^{1,2}$, LI Peng ${ }^{1}$
}

1. Institute of Geographic Sciences and Natural Resources Research, CAS, Beijing 100101, China;

2. College of Resources and Environment, University of Chinese Academy of Sciences, Beijing 100049, China;

3. Collaborative Innovation Center for Geopolitical Setting of Southwest China and Borderland Development, Kunming 650500, China;

4. University of Chinese Academy of Sciences, Beijing 100049, China

\begin{abstract}
Population geography (PopGeo), although a sub-discipline of human geography, should have been well developed in China in light of its national population size and unique demographic issues, regional socio-economic development, and biophysical differences. Yet it typically lags behind the development of its parent disciplines, especially demography and geography. Specifically, PopGeo in Chinese higher education is still at a low level in terms of the three major aspects of disciplinary development: academic majors for higher education, academic conferences, and journals. The research content of PopGeo in China has focused on the growth, composition, change, distribution, and carrying capacity of population at the meso- and macro-spatial scales. As the most populated country in the world, questions about how and why the population changes, where the population settles and migrates to, its maximum carrying capacity, and how to guide sound development of population matter to society and the economy, are always important topics in the PopGeo studies in China. In contrast, some new population phenomena such as human space-time behaviors (commuting, remittances, and friends' interaction), popular in the scientific community abroad, are not fully investigated at the micro-level. Presently, PopGeo in China may face both challenges and opportunities because of the adjustment of fertility policies and implementation of national new urbanization plans at the national level. It is this occasion that calls for a state-of-the-art review of the development of PopGeo since the 1980s, the turning point of an increasing number of PopGeo studies in China. We aim to reveal the current status of PopGeo in China to the world, and shed light on its further study.
\end{abstract}

Keywords: population geography; fertility policies adjustment; population aging; new urbanization; China

Received: 2016-01-12 Accepted: 2016-04-30

Foundation: Key Program of National Natural Science Foundation of China, No.41430861

Author: Feng Zhiming (1963-), PhD and Professor, specialized in regional sustainable development and efficient utilization of resources. E-mail: fengzm@igsnrr.ac.cn

*Corresponding author: Yang Yanzhao (1977-), PhD and Professor, specialized in regional sustainable development and efficient utilization of resources. E-mail: yangyz@igsnrr.ac.cn 


\section{Introduction}

As the most populous country in the world, China still has considerable demographic issues to be handled, such as sustained development of its population and resources (Chen and Chen, 2007), the population urbanization process (Zhu et al., 2008), migration in the dual social structure between urban and rural areas (Zhang and Song, 2003), and utilization of demographic dividends (Cai, 2010), etc. Ever since 1978, China has undergone epoch-making shifts in fertility policies, which exert significant influence on national and global population development (Feng et al., 2013; Wang, 2015). The Chinese government is gradually phasing out the one-child policy enforced in the 1980s to curb a once-surging population and limit resource demands, as well as alleviating socio-economic and environmental problems. In mid-November 2013, the "two-child fertility policy for couples where either the husband or the wife is from a single-child family" (called "single two-child" or "STC" hereafter) was formally implemented to relieve the process of population aging. The policy release was just a start in reflecting the central government's determination and actions for promoting long-term balanced development of the national population. However, the cautious and controllable attempt, literally understood as "wading across the stream by feeling the way," was not able to change the trend of population aging (Qiao, 2015; Wang, 2015). Two years later, the "universal two-child policy" (called "UTC" hereafter) was proposed to cope, in due course, with the aging trend. As a result, China is about to witness remarkable variations in its population growth rate, gender/age composition, and even population distribution for decades to come (Zhai et al., 2014). The new demographic issues induced by the fertility policies adjustment have accordingly become the foci of related disciplines, such as demography, sociology, geography, and economics.

Population Geography (PopGeo for short), a sub-discipline of human geography, is an interdisciplinary subject growing from geography, demography, sociology, and economics (Zhang, 2006). It studies population growth, population composition, and population change from a geographic perspective, and how and why these matter to society and the environment (Bailey, 2014; Zhang, 2006). The attribute of place-based or spatial change of population phenomena is the foremost feature that distinguishes it from its parent disciplines (Zhang, 2006). This often involves describing the reasons for population aggregation, the mechanisms of how demographic processes, including fertility, mortality, and migration, regulate population, and the interaction between population and economic development, ecological change, and other social issues (Bailey, 2014). Therefore, both existing problems and emerging challenges for policy shifts require continuously consistent and thorough investigations from the perspective of PopGeo. On the occasion of the International Geographical Congress held for the first time in China in 2016, and before looking ahead into the future, it is essential to comprehensively review the research progress in PopGeo in China since the 1980s; especially after the 35-year policies shift, this review can reveal not only the current status of PopGeo studies in China to the world, but also shed light on the further study fields of PopGeo in China.

\section{Differences in the foci of PopGeo studies at home and abroad}

The foci of PopGeo studies at home and abroad differ considerably because of the big dif- 
ferences in population size, population phenomena, and the stage of development in PopGeo.China, as the most heavily populated country, had been the largest agricultural nation but one with a relatively static population phenomenon. In contrast, developed Western countries became industrialized much earlier, which was accompanied by a dynamic population phenomenon.

\subsection{Overview of development processes of PopGeo}

To illustrate the differences between PopGeo studies at home and abroad, we first traced the major development processes of PopGeo studies in China and elsewhere to compare their diverse development patterns (Figure 1) and then summarized their recent research progress to measure the gap in PopGeo research between China and elsewhere.

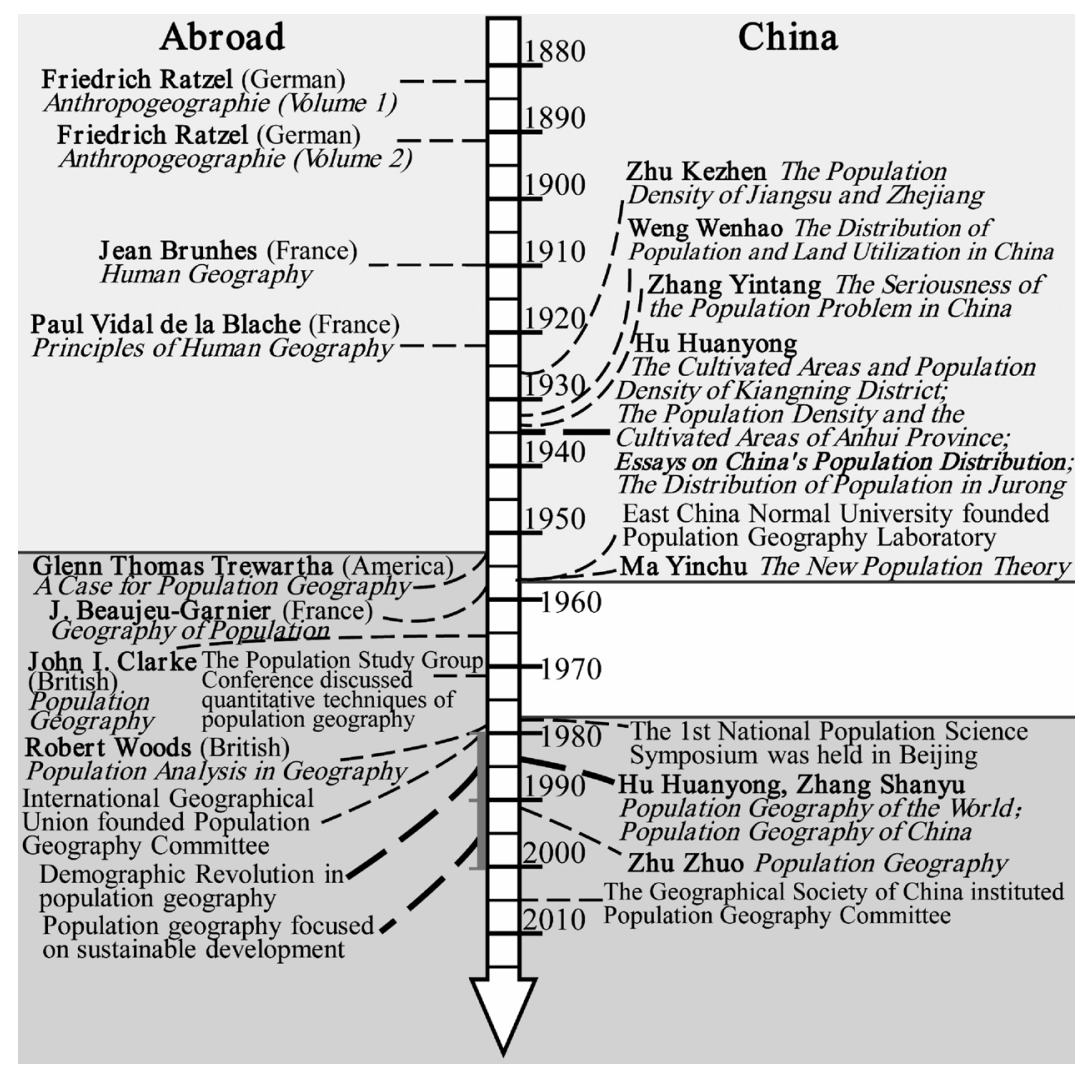

Figure 1 The development processes of PopGeo at home and abroad

According to Figure 1, PopGeo originated from humans' concern about the relationship between natural environment and population distribution. Friedrich Ratzel's two volumes of Anthropo-geographie (Ratzel, 1882; 1891) were regarded as the earliest classical works of PopGeo. Subsequently, Jean Brunhes and Paul Vidal de la Blache published Human Geography (Brunhes, 1912) and Principles of Human Geography (Blache et al., 1926), dedicating pages to elaborating fundamental issues in PopGeo. These geographers pioneered the scientific research of migration and population distribution, setting up PopGeo as a sub-discipline of human geography. Not until Glenn T. Trewartha's presidential address to the Association of American Geographers in 1953 (Trewartha, 1953) was PopGeo as a principal 
sub-discipline raised to the same level as human geography, thus bringing PopGeo to the stage of rapid development. Then, with J. Beaujeu-Garnier's Geography of Population (Beaujeu-Garnier, 1956), the first PopGeo treatise, and I. Clarke's Population Geography (Clarke, 1965), the first widely published PopGeo treatise in English, more and more books and papers devoted to PopGeo came off the press. In 1971, the Population Study Group Conference discussed the quantitative techniques of PopGeo at the University of Liverpool, marking a new era of quantitative study in PopGeo. However, Robert Woods negated Trewartha's PopGeo system insisted on the equal importance of fertility, mortality, and migration, which led to the extensive adoption of methodologies and theories in Demography, precluding the "demographic revolution" of PopGeo in the 1980s (Woods, 1979). Subsequent to the emergence of the energy shortage and environmental problems, population geographers focused more on sustainable development in the 1990s.

PopGeo as an independent discipline developed relatively late in China, given the abrupt halt caused by the decade of turmoil between the 1960s and 1970s. Yet for all that, Chinese geographers' unremitting efforts allowed PopGeo in China to catch up with advances at the world level. For instance, Zhu Kezhen's The Population Density of Jiangsu and Zhejiang (Zhu, 1926) was regarded as the foundation of China's PopGeo, and was then followed by Weng Wenhao's (Weng, 1932) and Zhang Yintang's (Zhang, 1934) concern about Chinese population. Hu Huanyong is an eminent scholar in China's PopGeo. He studied under French human geographer Albert Demangeon and then returned to China to devote his whole career to promoting PopGeo as an independent subject. Then, Hu Huanyong did considerable research in population distribution and the man-land relationship during the 1930s (Hu, 1934; Hu, 1935a; Hu, 1935b; Hu, 1936). Most importantly, the Heihe-Tengchong Line, first reported in the publication Essays on China's Population Distribution-later known internationally as the "Hu Line"-marked a striking difference in the distribution of China's population. In 1957, he presided over the foundation of the Population Geography Laboratory of East China Normal University, the first population geography laboratory in China. However, along with Ma Yinchu's The New Population Theory (Ma, 1957), his work was harshly criticized by Chinese government; PopGeo was halted for decades. Not until the First National Population Science Symposium, held in Beijing, did China's PopGeo recover and go on to further success. Hu Huanyong and Zhang Shanyu collectively compiled Population Geography of the World (Hu and Zhang, 1982) and Population Geography of China (Hu and Zhang, 1986), leading to a boom in PopGeo study. In 2005, the Geographical Society of China, the most authoritative academic society in geography of China, formed the Population Geography Committee, marking the maturity of China's PopGeo.

A comparison of the different development processes of PopGeo at home and abroad (Figure 1) shows that China's PopGeo was established much later, by nearly a half century, than the developed Western countries. At the early stage, the introduction and development of this discipline were typically influenced by the West, especially Germany and France, where PopGeo was established as an integral and independent subject system in the early 20 th century. However, after a very short booming period in the 1950s, China's PopGeo promptly lagged for two decades because of ideological and political reasons, further widening the gap between China and the West. Fortunately, owing to the Chinese population geographers' tremendous efforts, especially those by Hu Huanyong and Zhang Shanyu, 
PopGeo in China resuscitated the discipline and it gradually caught up with the new trends, such as the emphasis on quantitative techniques and application of demographic methodology, during the last two decades of the 20th century. Despite the fact that PopGeo is still a sub-discipline of human geography in China, given the size, temporal dynamics, and spatial differences of its population, we have sound reasons to believe that China's PopGeo will steadily progress in the 21 st century.

\subsection{Comparison of research foci in PopGeo}

At the most basic level, PopGeo is concerned with fertility, mortality, and migration (Bailey, 2014; Gaile and Willmott, 2003; Willmott, 1989). On the one hand, PopGeo, as Adrian Bailey has explained, has been dominated by four principal research fields: measures of and depictions of population agglomeration; the study of urban population; overpopulation and density; and analyses of population characteristics (Bailey, 2014). On the other hand, PopGeo has a long, productive relationship with the subject of migration (Collyer et al., 2012; Smith and King, 2012), as population geographers continue to make significant strides in understanding human spatial mobility on a variety of scales. It aims to demonstrate that the view of migration may be interwoven with current interests in issues of nationality, identity, community and the combination of different methodologies. Moreover, migration remains the area where geographers make the most notable and increasingly original contributions. Scholars abroad have studied migration from diverse aspects: for example, 'illegal' migrants (Anderson and Ruhs, 2010), detention (Silverman and Massa, 2012), 'transit' migrants (Collyer et al., 2012), and domestic workers (Yeoh and Huang, 2010), which are all research objects on which geographers focus.

However, as migration prevails in PopGeo, fertility- and mortality-related studies seem to be dwarfed in China. This phenomenon can be explained by the following factors. First, population migration has been one of the major types of flow in the world, because of economic globalization. The frequent mobility not only indicates great economic ties and social communication, but also increases the risk of spread of epidemics, unequal spatial gender ratios, the imbalance of labor forces, and social inequity. Second, with the birth rate continuously declining, relatively few population geographers focus on contemporary fertility research in "the North," especially in Britain and the U.S., while interest in historical patterns of fertility change in Europe and contemporary fertility patterns in "the South" continues to rise (Boyle, 2014). Third, mortality study is fortunately enjoying a renaissance, which is embodied by the soaring number of studies on necropolitics, thanatopolitics, and "deathscapes", as well as the inequalities of premature death (Tyner, 2014).

Meanwhile, as social development and environmental conservation become the mainstream consensus, the migration-development nexus and population-environment relationship are promoted as two of the most engaging and promising relationship issues on which PopGeo scholars can embark (Bailey, 2010; Conway, 2004;). These two inter-science initiatives require multidisciplinary cooperation and interaction, which will also drive the multidisciplinary integration of PopGeo. At the same time, more and more human space-time behaviors, such as commuting, remittance, and friends' interaction, are being recorded and discussed by the rapid advance and uptake of Information and Communications Technologies, e.g., Skype, Tweet, and social networking sites (Kellerman, 2010). Such technological 
developments allow the formation of multiple social bonds to be simultaneously forged and maintained across different socio-spatial contexts, thereby amplifying the opportunities for migration study in PopGeo (Bailey, 2014). This new tendency gives PopGeo a great opportunity to expand its influence in the social sciences as well as challenge the construction of new theories making sense of the interconnections between technological advancement and human spatial-temporal activities.

As for China's PopGeo development in recent decades, it has enjoyed sustained and rapid advancement, due to the Chinese government's focused attention on population issues and the noteworthy improvement of census data quality and research techniques. First, the advancement in authority, precision, and integrity of China's censuses and other standard data collections in the region give scholars opportunities to work on China's population distribution and structure on various scales. Moreover, the popularization of remote sensing, geographical information systems, and global positioning systems in PopGeo research not only enhances the spatial consciousness among many Chinese population researchers and policymakers, but also facilitates the spatial-temporal analysis in China's PopGeo study.

On account of China's own socio-economic status, Chinese population geographers conduct research on different features from abroad and generate distinctive research patterns. Traditional PopGeo studies elaborated the static population distribution inherited from $\mathrm{Hu}$ Huanyong's classical research, such as the fitness of the nationwide population distribution structure with the $\mathrm{Hu}$ Line (Qi et al., 2015), and the population proportion of dual urban-rural systems(Wang et al., 2016), etc. Compared with foreign scholars' concern about human health, such as disease propagation and mortality, Chinese geographers focus more on fertility and demographic structures, especially age structures, owning to the pressure from family planning policies. Population geographers at home and abroad reach a consensus in the emphasis on studying the population-environment relationship and population carrying capacity, as the consequence of a deteriorating living environment. However, there still exists a large gap in migration studies between China and the rest of the world. Migration studies at the regional to intercontinental scale are all well conducted by international population geographers, while Chinese scholars emphatically study migration between provinces and within the region, mainly because of the opaqueness of the census data. Nevertheless, the emergence of new mediums for recording human spatial-temporal behaviors is a prime opportunity for Chinese population geographers to catch up. It is worth mentioning that many Chinese forward-thinking scholars are already devoted to human movement studies based on data from remittances, public transportation (Liu et al., 2012), and map positioning and social media (Liu et al., 2014).

\section{Current status of PopGeo in Chinese higher education}

In this section, the development of PopGeo in China is analyzed according to three characteristics: namely, as an academic major in higher education, journals, and academic conferences. These aspects basically reflect the discipline's development.

\subsection{Major setting for higher education}

Training professional talent is paramount to the development of a discipline. As a sub-disci- 
pline of human geography in China, PopGeo has not been available as an academic specialty in colleges and universities. Currently, without systematic academic training for young scholars, especially undergraduates and graduates, PopGeo research work is typically carried out as a research direction within the academic community. For instance, Mr. Hu Huanyong, East China Normal University, promoted the establishment of the only doctoral program and post-doctoral research station for PopGeo. In contrast, demography, a sub-discipline of Sociology, focuses on population development and its relationships with society, the economy, and the environment, and shows strong growth momentum. For example, there are 33 population-related research centers in China that have joined the Committee for International Cooperation in National Research in Demography (CICRED, http://www.cicred.org/).

\subsection{PopGeo-related journals}

Academic journals provide a platform for reporting and circulating the latest research progress. Presently, no special professional journal is issued for PopGeo studies in China. Chinese population geographers have to publish their works in journals specialized in geography, resources, and demographic sciences, such as the Journal of Geographical Sciences (English), Chinese Geographical Science (English), Chinese Journal of Population Resources and Environment (English), Acta Geographica Sinica (Chinese), Population Research (Chinese) and China Population Today (Chinese). This awkward situation greatly marginalizes PopGeo studies and reduces its importance. In contrast, a few professional PopGeo journals are available globally, including Population, Space and Place (PSP), a journal of the Population Geography Research Group (PGRG), formerly known as the International Journal of Population Geography. PSP is the leading English-language research journal in the field of PopGeo.

\subsection{Conferences for PopGeo}

Academic symposiums on PopGeo studies in China are neither active nor frequently reported. In 2015, two symposiums related to the Hu Line were held in Tengchong City, Yunnan Province, entitled "Spatial Demography: Theory, Method and Demonstration" and, in East China Normal University, Shanghai, "Symposium on Population Geography and the Future of Urbanization in China: Symposium for Commemorating the 80th Anniversary of the Discovery of Hu Huanyong Line." In contrast, the International Conference on Population Geographies, the foremost international gathering specialized in PopGeo, has been held eight times at two-year intervals since 2001. In 2016, as one of the IGU commissions, PopGeo set 6 sessions, varying from demographic divide to migration. They contained 83 oral presentations and 20 poster presentations, of which 35 oral presentations and 14 poster presentations were performed by Chinese scholars. In the past, China's PopGeo-related academic meetings were held as sessions of the annual conferences organized by the Geographical Society of China, China Society of Natural Resources, and China Population Association. In 2005, the establishment of the Population Geography Committee under the Geographical Society of China greatly promoted academic communication for population geographers, although we have lagged behind the International Geographical Union for over two decades. 
In summary, the current development of PopGeo in China is still at a low level, which does not tally with the facts of its huge population size, increasingly floating population, population aging, regionally unbalanced urbanization level, and fertility policy adjustments.

\section{Research progress in PopGeo in China}

Because of the late development of PopGeo and the complexity of China's population phenomenon, PopGeo studies in the last decades paid much attention to population size and carrying capacity, growth rate and fertility policy adjustment, population composition and aging, population change and migration, population distribution and urbanization, and labor force evaluation. Here, we have tried to systematically review the four most common research topics, i.e. population distribution, change, migration, and carrying capacity. As for the problems of aging and urbanization discussed in Section 5, we argue that they are both challenges and opportunities for the development of PopGeo.

\subsection{Geographical distribution of the Chinese population}

This topic typically refers to research that applies data from the population census statistics or demographics to reveal the spatial differences in population distribution on a regional to national scale; it is followed by investigations into the related biophysical, cultural, and socio-economic driving forces, and the discovery of laws governing the disequilibrium of population distribution on different scales.

Delineating the spatial disparities of global population distribution is a continuous and unending topic (NRC, 2010). China has a complex biophysical environment latitudinally, longitudinally, and altitudinally, as well as diverse ethnic groups. As a traditional agricultural country in the past, particularly one influenced by the centuries-old concept of "more sons, more blessings," China's population, on the whole, has increased at a distinct pace during different periods (Pan et al., 2013) and to date China is the most populous country. China is hence the first nation in the world to officially record demographics as early as the end of the 22nd century BC ( $\mathrm{Hu}, 1982)$. Historically, the distribution of the vast Chinese population was relatively stable, except in the case of uncontrollable events, such as civil wars (Hu, 1982), policy malfunctions (Zhang, 2002), and sudden climate changes (Wu and Wang, 2008).

In the 1930s, Hu Huanyong, the founder of PopGeo in China (Feng and Li, 2011; Ge and Feng, 2008), drew the "Hu Line," which first delineated the striking differences in population distribution between the northwest and the southeast of China's territory (Hu, 1935b). According to the $\mathrm{Hu}$ Line, about 4.59 million people or $96 \%$ of the Sino population, an extremely high proportion, were settled densely in the eastern half of China in the early 1930s; this was mainly in the lower-elevation regions that had only $36 \%$ of the total area (about 11 million $\mathrm{km}^{2}$ ), while a mere $4 \%$ of the population were sparsely scattered in the spacious western part (64\%) of the $\mathrm{Hu}$ Line, typically occupied by plateaus, deserts, and mountains (Hu, 1935b). An agent-based model simulation indicated that there were two major shifts of population distribution over the past 2000 years in China ( $\mathrm{Wu}$ and Wang, 2008). One was the first excessive movement of the southern Sino population versus that in northern China around 910 AD with the Anshi Turmoil as the major incentive; the other was the formation 
of the prototype of the Hu Line, which differentiated the population distribution pattern in the west versus the east of China and was primarily motivated by drastic climate change during 1230-1260 AD (Wu and Wang, 2008). Since the rise of the Hu Line, it has been widely used to demarcate the vast longitudinal variations in farmland and agricultural labor (Liu and Li, 2010), economic development (Li and Wei, 2010), and aerosols (Zheng et al., 2012).

Over the following 80 years, the Chinese population was more than doubled, from 0.60 billion in 1953 to 1.33 billion in 2010, albeit in a reduced territorial area of 9.63 million $\mathrm{km}^{2}$. Thereafter, many scientists have successively re-examined the changes in spatial pattern of the national population using Chinese demographics officially surveyed in 1953, 1964, 1982 (Hu, 1990; Yang, 1993), 1990 (Li, 1993), 2000 (Ge and Feng, 2008), and 2010 (Qi et al., 2015). As expected, the overall geographical distribution disequilibrium of the Sino population did not change conspicuously (Ge and Feng, 2008; Hu, 1990; Qi et al., 2015; Wang, 1998), and will retain the overall pattern in the near future until a population peak arrives (Wang et al., 2014). However, the disequilibrium was worse because over $75 \%$ of the Sino population was highly concentrated in less than $20 \%$ of the total territorial area and more than half the land was settled by less than $2 \%$ of the population (Ge and Feng, 2009). The population ratio of the west versus the east generally maintains itself at a rate of $6 \%$ versus 94\% (Ge and Feng, 2008; Qi et al., 2015), although there are certain drastic changes at the local to regional scale. As the distribution pattern of the Chinese population is generally fixed, considerable attention is currently being paid to delineating the changes and differences at the county or regional levels, such as its suitability (Feng et al., 2014b), restriction of natural resources (Feng et al., 2014a; Feng et al., 2014c), and population density (Wang et al., 2015).

\subsection{Natural change in the population}

This topic examines the regional variations in natural population alterations and their relationship with socio-economic development. China's population had made up around $20 \%$ of the global population since 1978, although this proportion is declining slightly. During 1978-2013, the total population increased from 960 million to 1.37 billion, while the annual population growth rate decreased from $12 \%$ to $4.9 \%$, with an urbanization rate increasing from $17.9 \%$ to $53.7 \%$.

Population has dual attributes of production and consumption that are closely related to economic progress. The robust development of a national economy lays a solid basis for raising a growing population and improving population quality. As one of key elements of production, a growing population will also greatly stimulate economic development. However, Chinese population change has promoted high-speed economic growth in four respects (Wang and Chen, 2010): namely, by establishing an enormous and expanding consumer market, providing an adequate and competent labor force (Liu and Shen, 2013), promoting the optimization of production elements and the rise of agglomerative benefits, and offering rich demographic dividends (Cai, 2010). As every coin has two sides, the introduction of reform and opening-up process is a positive spur to rapid economic growth in the eastern coastal regions, but negatively enlarges the geographical economic disparities across the country, especially between eastern and western parts. It is, then, quite normal to see a large 
floating population across the country springing up to seek better development opportunities. There were several major trends of recurrent population change (Duan et al., 2008), e.g., universalization of population mobility, economically driven flow, long duration of movement, coastal concentration of inflow, and an adult-oriented, gender-balanced, household-based mobility. The increased and frequent population mobility has raised many problems of resource arrangements and social equity in city management, especially in the megalopolis.

According to the medium and low population projections from the UN World Population Prospects (2010 version), China is going to face substantial population decreases and population aging in the 21 st century. A further series of issues, such as the disappearance of the demographic dividend, the negative growth in the working-age population, a declining fertility rate, and urban management will be caused by floating population. Future population change may also exert extensive impacts on population spatial distribution, economic growth, and urbanization (Zuo, 2012). How to deal with the challenges of an aging society will remain a longstanding task.

\subsection{Population migration}

The topic of population migration focuses on the direction, flow, and intensity of population movement, and is also concerned with regional disparities, driving forces, and their consequences. Compared to the theme of population distribution-a static description of the location and settlement of population-population migration aims to delineate the dynamics of population movement. China being an age-old agricultural country, large-scale internal migration in the past occurred infrequently, with the exception of war conflicts. Since the 1950s, the household registration system (or Hukou) has established an invisible wall to demarcate different places of residence so as to control population migration, especially between urban and rural areas (Chan, 2010). However, economic and market reforms since the late 1970s have enlarged the regional disparity of economic development on one side (Fan and Sun, 2008), overstepped the invisible wall specifically, and brought about a surge in internal migration in China (Wu and Zhang, 2015). Recent study suggested that in Hukou reform-era, the household registration system is still intertwined with market mechanism to influence China's migration (Liu and Xu, 2017).

Interprovincial migration has been the principal category in China during the last three decades (Ding et al., 2005; Li et al., 2014), and it leads to regional differences, especially between the north and the south, as well as among the western, central, and eastern regions. At the interprovincial level, the developed eastern provinces-Beijing, Tianjin, Jiangsu, Shanghai, Zhejiang, Fujian and Guangdong-and the northwest province that is opening up-Xinjiang Uyghur Autonomous Region-are currently the two regions showing net migration (in-migration versus out-migration) gains, while the other provinces, especially those in the central and western regions, show net migration losses (Ding et al., 2005; Li et al., 2014). Study also indicated that with better employment opportunities, temporary migrants are increasingly concentrated in southeast coastal provinces, whereas permanent migrants tend to move to south-central and southwestern provinces with a low entry barrier and numerous return migrants (Liu and $\mathrm{Xu}, 2017$ ). At the regional level, migration in the south was more active than its counterpart in the north owing to biophysical and cultural factors (Ding et al., 
2005; Li et al., 2014). However, out-migration from the central regions to the eastern and western provinces was primarily caused by income-induced job-hunting or employment (Liu et al., 2014;Xiang, 2007), and by social events including moving to be near relatives, marriage, and education or training (Ding et al., 2005). Among the four categories of Chinese administrative units - namely, province, prefecture, county, and town-population migration at the prefectural city level mostly reveals spatial dynamics (Wang et al., 2012b). However, under the stringent disclosure policy with regard to socioeconomic data in China, only the inter-provincial migration data are publicly accessible. Therefore, reliable simulation model of migration is of importance in migration study of China (Li et al., 2017). Meanwhile, with the maturity of the research of domestic migration, Chinses scholars now are plunging into the area of international migration, especially the overseas returnee (Wang et al., 2015).

The general trend of interprovincial migration in China has remained relatively stable since 1978, in spite of some local adjustments after the 1990s (Wang et al., 2012a). In the near future, this trend will not change substantially because of the interprovincial and regional disparities in urbanization and economic levels. Education enhances the possibility of migrants being accepted in the new socio-spatial environment. Geographic mobility, however, does not undermine place-based attachment but tends to attenuate its intensity (Du, 2017). It therefore displays a similar trend to the national population distribution as they are both deeply influenced by China's biophysical environment and economic development. To narrow the regional gaps, the Chinese government put forward the West Development Strategy (1999) and the Rising Strategy in Central Region (2004), but the overall spatial pattern of regional economic development did not change significantly (Wang et al., 2012a).

\subsection{Population carrying capacity}

It has been about a century since the proposal of a term for carrying capacity (Park and Burgess, 1921). However, this term extended into the domain of population carrying capacity (PCC) or human carrying capacity (HCC), which emerged in the book Road to Survival (Vogt and Baruch, 1948). In 1978, the Food and Agricultural Organization of the United Nations (FAO) first proposed agro-ecological zoning (AEZ) methodology to determine agricultural production potentials and the carrying capacity of land resources at the global, regional, national, and sub-national levels. In the 1980s, the United Nations Educational, Scientific, and Cultural Organization (UNESCO), and the FAO defined carrying capacity as the population, at any moment in time, which can be indefinitely sustained at a given standard of living (UNESCO et al., 1985). Thus, concern about the PCC in the world or within a nation has never been suspended. Notably, how many people can the Earth support (Cohen, 1995)? Who will feed China (Brown, 1995)?

China has been a densely populated country ever since the 1850 s. It is not surprising to notice that research on PCC or HCC has always been an important and pressing matter in the eyes of policymakers and the scientific community ( $\mathrm{Lu}$ and Guo, 1998). Apart from the topic of population geographical distribution, the number of PCC- or HCC-related studies ranked second in the fields of PopGeo in China. These studies estimated the PCC or HCC at regional (and particularly urban) to national scales using either a single natural resource, such as land (Feng, 1993; Feng, 1994), water (Tong, 2010), or minerals (Wang, 1998), or multiple natural resources. 
The PCC of land resources in China began in the late 1980s with the release of the Report of the Productivity and Population Carrying Capacity of the Land Resources in China in 1991 (Chen, 1991). The foremost conclusions derived from the five-year research work were the maximum PCC in China of 1.6 billion and the optimum population of 0.7 billion. This project typically predicted the maximum population by quantifying the food production and supply potential. Similar studies on the PCC valuation in regions disturbed by natural disasters, like those with earthquakes, also based the figure on the total amount of farmland for productivity (Gao et al., 2010). In addition, another study also showed that food availability best determined the HCC (Russell, 2003). Ever since the national project, the PCC of land was widely evaluated across the country, especially at the local to regional level. More accurate estimates were made about the PCC. For example, the HCC of China's agro-ecosystem was predicted to be about $7.5 \%$ more than the national estimate (Cao et al., 1995). The resultant PCC gradually becomes the basic information for territorial space planning (Jin et al., 2013), major function-oriented zoning (Fan and Li, 2009), and population development functional zoning. Other research work on the carrying capacity of water and mineral resources also estimated the potential population supporting capacity; however, the reasonable and sustainable socio-economic development scale was given more attention (Duan et al., 2010; Liu et al., 2011; Wang, 1998).

With rapid urbanization accompanying urban diseases in China, urban carrying capacity (UCC) becomes a hot topic for studies on carrying capacity (Shi et al., 2013). The city, with its unique natural and human complexity, is given top priority for comprehensive carrying capacity in urbanized areas. Debates on the quantification of comprehensive UCC involved many approaches. For instance, an integrated carrying capacity index consists of three aspects of support, pressure, and adjustment, which were used to evaluate UCC in Changzhou city (Wang et al., 2011). Considering the inconsistency between traditional PCC analysis and actual urban problems, an employment-oriented perspective that views related economic factors as the direct drivers and the others as indirect was proposed to evaluate UCC (Liu et al., 2013; Luo et al., 2013).

However, several issues emerged as the research into PCC or HCC proceeded on various theoretical and methodological fronts. First, the limitation of multiple theoretical hypotheses for PCC or HCC usually creates huge difficulty for positively validating the modeling results (Tong, 2012). Second, as PCC or HCC assessment is related to various factors, the tradeoff during their selection and different approaches to evaluation generally lead to distinct and incomparable results (Shi et al., 2013). Under these conditions, negative or hostile voices questioning the necessity for PCC or HCC research work emerged (Tong, 2012; Shi et al., 2013). Everything has two sides. These doubts and questions about the basis of PCC or HCC studies may motivate PopGeo scientists in China to attach positive importance to theoretical and methodological investigations.

\section{Challenges and opportunities of PopGeo in China}

\subsection{Fertility policy adjustment and population aging}

Population fertility policy adjustments in China from the "family planning policy," or the "one-child policy," in place for 30 years since the late 1970s, to the STC and the UTC are 
both opportunities and challenges for PopGeo studies. Currently, with regard to the STC, there has been much debate on the quantity of targeted population, and also on the accumulated couples (Yao et al., 2014), spatial distribution of fertility release (Yao et al., 2014), amount of annual newborn population (Wang and Zhang, 2012; Qiao, 2014a), and total fertility rate (Wang, 2015). Experience from one-year implementation of the STC showed that a low fertility rate was beyond our rate of precipitation (Qiao, 2015). With the latest UTC gradually opening up across the country, it will optimize the demographic structure, increase the labor supply, and ease pressure from the aging population (Zhai et al., 2014). There is a pressing need to investigate the demographic and social consequences of an immediate transition to a UTC, especially in the next decades. Literature reviewed showed that researchers in demography, sociology, and economics have carried out a series of research work on whether or when there is a baby boom according to the coming fertility policy (Qiao, 2014b), fertility intentions ( $\mathrm{Li}$ and Zhai, 2014), fertility behavior, and fertility levels(Gu, 2011; Yin et al., 2014), the effects on the sex ratio at birth, labor force supply, and population aging easing in the future (Zhai et al., 2014). Meanwhile, population geographers in China also studied the carrying capacity of land resources (especially farmland), water resources, energy consumption, carbon emissions and the eco-environment under the scenario of UTC. They showed that the newly increased population attributable to the UTC basically will not exceed the maximum carrying capacity in the future, although displaying a somewhat tightly balanced status. However, PopGeo in China should play a greater role in examining the spatial dynamics of population distribution, composition, alternation, and migration under the new fertility policy.

\subsection{The Hu Line and Chinese urbanization}

From the perspective of population urbanization, the urbanization rate in China reached $50 \%$ in 2010 and 54.8\% in 2014 (NBSC, 2014). However, urbanization levels at the provincial and regional scales differ greatly across the country as a whole. In 2013, the average urbanization rates in East, Central, and West China were $67 \%, 52 \%$, and $44 \%$, respectively (NBSC, 2014). This can be fully verified by a recent review summarizing Chinese regional urbanization (Gu et al., 2012). Specifically, most research works on urbanization were reported at the provincial and municipal levels in East China, particularly in the Pearl River Delta and the Yangtze River Delta, while only a few were reported in Central and West China. The huge disparity in regional urbanization levels is determined by the level of economic development (Zhao and Wang, 2015). How to decrease the economic gap and narrow the income gap between coastal and inland areas will be the center of gravity for the central government.

The Hu Line was originally proposed to delineate the distinct west-east variations in population distribution. Actually, this Line gradually proved to be closely connected with the west-east differences concerning the following aspects: mean annual precipitation (400 mm isoline), arable land, and the unbalanced development in transportation and economy. However, after 80 years, this Line has also become the geographical dividing line of urbanization levels. Urbanization level is perceived as an important indicator symbolizing regional economic levels and potential. Ever since the discovery of the Line, almost, debates about whether this important Line can be broken or not remained. This scientific issue was raised 
to a political level, especially when the current Chinese Premier Li Keqiang questioned whether and how the Line could be broken in 2014 .

Recently, the Chinese government officially issued the "National Plan on New Urbanization (2014-2020)," the first urbanization plan enacted by the central authorities. The Plan aims to gradually settle the former agricultural population who have migrated to the cities, optimize urbanization patterns, increase the sustainability of cities, and promote integration of urban and rural development. Experts believe the likelihood that the new urbanization plan is about to breakthrough the Hu Line is an important impetus at the top level (Ma, 2015; Zhang et al., 2015). However, there is still a long way to go. Since the Line has transcended the scope of PopGeo and become a social, economic, cultural, and biophysical boundary nationally, it can be anticipated that $\mathrm{Hu}$ Line-directed studies will be enhanced and deepened in the future.

\section{Summary}

Population Geography should have been well developed in China in light of its unique population issues and regional disparities in economic development. In fact, PopGeo studies seem to be marginalized in the fields of geography and resources sciences on the one hand, while on the other hand, they are dwarfed by the analyses in demography or sociology. Comparatively speaking, PopGeo studies in China lag behind those of developed Western countries as we still focus on the description, explanation, and forecasting of population phenomena from the provincial to regional scales. More efforts should be made to facilitate the transition from static descriptions and explanations to dynamic modeling of population migration mechanisms. Currently, PopGeo studies in China may face both challenges and opportunities due to the adjustment of fertility policies and the implementation of a new national urbanization plan. Chinese population geographers may grasp the opportunity to initiate a new round of disciplinary development. On the occasion of the concluding of International Geographical Congress, convened for the first time in China in 2016, and the unremitting research interests in PopGeo studies, we have briefly reviewed the progress, challenges, and opportunities for the development of PopGeo since the reform and opening-up in the 1980s.

\section{Acknowledgment}

The authors express sincere gratitude to Professor Shuming Bao from the China Data Center, University of Michigan, for valuable suggestions concerning this manuscript.

\section{References}

Anderson B, Ruhs M, 2010. Researching illegality and labour migration. Population, Space and Place, 16(3): $175-179$.

Bailey A, 2014. Making Population Geography. New York: Routledge, 256.

Bailey A J, 2010. Population geographies, gender, and the migration-development nexus. Progress in Human Geography, 34(3): 375-386.

Beaujeu-Garnier J, 1956. Géographie de la Population. Paris: MT Génin.

Blache P V D L, Martonne E D, Bingham M T, 1926. Principles of Human Geography. New York: Henry Holt 
and Company, 511.

Boyle O, 2014. Population geography: Does geography matter in fertility research? Progress in Human Geography, 27(5): 615-626.

Brown L R, 1995. Who Will Feed China: Wake-Up Call for a Small Planet. New York: W. W. Norton \& Company, 168.

Brunhes J, 1912. La Géographie Humaine: Essai de Classification Positive, Principes et Exemples. Paris: Librairie Félix Alcan.

Cai F, 2010. Demographic transition, demographic dividend, and Lewis turning point in China. China Economic Journal, 3(2): 107-119.

Cao M, Ma S, Han C, 1995. Potential productivity and human carrying capacity of an agro-ecosystem: An analysis of food production potential of China. Agricultural Systems, 47(4): 387-414.

Chan K W, 2010. The household registration system and migrant labor in China: Notes on a debate. Population \& Development Review, 36(2): 357-364.

Chen B, 1991. An outline of the research method of the project "The productivity and population carrying capacity of the land resources in China." Journal of Natural Resources, 6(3): 197-205. (in Chinese)

Chen J, Chen J, 2007. Rapid urbanization in China: A real challenge to soil protection and food security. Catena, 69(1): 1-15.

Clarke J I, 1965. Population Geography. Oxford: Pergamon Press.

Cohen J E, 1995. How many people can the earth support? The Sciences, 35(6): 18-23.

Collyer M, Düvell F, Haas H, 2012. Critical approaches to transit migration. Population, Space and Place, 18(4): 407-414.

Conway D, 2004. On being part of population geography's future: Population-environment relationships and inter-science initiatives. Population, Space and Place, 10(4): 295-302.

Ding J, Liu Z, Cheng D et al., 2005. Areal differentiation of inter-provincial migration in China and characteristics of the flow field. Acta Geographica Sinica, 60(1): 106-114. (in Chinese)

Du H, 2017. Place Attachment and Belonging among Educated Young Migrants and Returnees: the Case of Chaohu, China. Population, Space and Place, 23: e1967.

Duan C, Liu C, Chen X et al., 2010. Preliminary research on regional water resources carrying capacity conception and method. Acta Geographica Sinica, 65(1): 82-90. (in Chinese)

Duan C, Yang G, Zhang F et al., 2008. Nine trends of changes of China's floating population since the adoption of the reform and opening-up policy. Population Research, 32(6): 30-43. (in Chinese)

Fan C C, Sun M, 2008. Regional inequality in China, 1978-2006. Eurasian Geography and Economics, 49(1): $1-18$.

Fan J, Li P, 2009. The scientific foundation of Major Function Oriented Zoning in China. Journal of Geographical Sciences, 19(5): 515-531. (in Chinese)

Feng W, Cai Y, Gu B, 2013. Population, policy, and politics: How will history judge China's one-child policy? Population and Development Review, 38(S1): 115-129.

Feng Z, 1993. The origin and development of the land carrying capacity research. Resources Science, (6): 74-78. (in Chinese)

Feng Z, 1994. Past, present and future of land resources carrying capacity studies. China Land Science, 8(3): 1-9. (in Chinese)

Feng Z, Li P, 2011. Review of population geography in the past century. Progress in Geography, 30(2): 131-140. (in Chinese)

Feng Z, Yang Y, You Z, 2014a. Research on land resources restriction on population distribution in China, 2000-2010. Geographical Research, 33(8): 1395-1405. (in Chinese)

Feng Z, Yang Y, You Z et al., 2014b. Research on the suitability of population distribution at the county level in China. Acta Geographica Sinica, 69(6): 723-737. (in Chinese)

Feng Z, Yang Y, You Z, 2014c. Research on the water resources restriction on population distribution in China. Journal of Natural Resources, 29(10): 1637-1648. (in Chinese)

Gaile G L, Willmott C J, 2003. Geography in America at the Dawn of the 21st Century. Oxford: Oxford University Press, 848 .

Gao X, Chen T, Fan J, 2010. Population capacity in the Wenchuan Earthquake reconstruction areas. Acta Geographica Sinica, 65(2): 164-176. (in Chinese)

Ge M, Feng Z, 2008. GIS-based analysis of spatial pattern of China's population in 2000: Comparison with Hu 
Huanyong's study in 1935. Population Research, 32(1): 51-57. (in Chinese)

Ge M, Feng Z, 2009. Population distribution of China based on GIS: Classification of population densities and curve of population gravity centers. Acta Geographica Sinica, 64(2): 202-210. (in Chinese)

Gu B, 2011. Fertility intention, fertility behavior and fertility level. Population Research, 35(2): 43-59. (in Chinese)

$\mathrm{Gu}$ C, Wu L, Ian C, 2012. Progress in research on Chinese urbanization. Frontiers of Architectural Research, 1(2): $101-149$.

$\mathrm{Hu}$ H, 1934. The cultivated areas and population density of Kiangning District. Acta Geographica Sinica, 1(2): 1-26. (in Chinese)

$\mathrm{Hu} \mathrm{H}, 1935 \mathrm{a}$. The population density and the cultivated areas of Anhui Province. Acta Geographica Sinica, 2(1): 53-62. (in Chinese)

$\mathrm{Hu}$ H, 1935b. The distribution of China's population. Acta Geographica Sinica, 2(2): 33-74. (in Chinese)

$\mathrm{Hu} \mathrm{H}, 1936$. The distribution of population in ChuYung. Acta Geographica Sinica, 3(3): 621-627. (in Chinese)

$\mathrm{Hu}$ H, 1982. Summary of geographical distribution of the Chinese population. Population Research, (4): 25-29. (in Chinese)

$\mathrm{Hu}$ H, 1990. Distribution, regionalization and prospect of China's population. Acta Geographica Sinica, 45(2): 139-145. (in Chinese)

$\mathrm{Hu}$ H, Zhang S, 1982. Population Geography of the World. Shanghai: East China Normal University Press, 364. (in Chinese)

$\mathrm{Hu}$ H, Zhang S, 1986. Population Geography of China. Shanghai: East China Normal University Press, 452. (in Chinese)

Jin G, Wang Z, Yao X et al., 2013. Concept and methods for spatial zoning. China Land Sciences, 27(5): 48-53. (in Chinese)

Kellerman A, 2010. Mobile broadband services and the availability of instant access to cyberspace. Environment and Planning A, 42(12): 2990.

Li F, Feng Z, Li P, et al., 2017. Measuring directional urban spatial interaction in China: A migration perspective. PLoS One, 12(1): e0171107.

Li L, Zhai Z, 2014. Does the birth of first child weaken the fertility desire of second child: Evidence from the couples with one side without siblings. South China Population, 29(5): 1-11. (in Chinese)

Li R, 1993. Change characteristics of population distribution in China during 1982-1990. South China Population, (1): 20-25. (in Chinese)

Li Y, Liu H, Tang Q et al., 2014. Spatial-temporal patterns of China's interprovincial migration, 1985-2010. Journal of Geographical Sciences, 24(5): 907-923. (in Chinese)

Li Y, Wei Y H D, 2010. The spatial-temporal hierarchy of regional inequality of China. Applied Geography, 30(3): 303-316.

Liu J, Dong S, Li Z, 2011. Comprehensive evaluation of China's water resources carrying capacity. Journal of Natural Resources, 26(2): 258-269. (in Chinese)

Liu Y, Kang C, Gao S et al., 2012. Understanding intra-urban trip patterns from taxi trajectory data. Journal of Geographical Systems, 14(4): 463-483.

Liu Y, Li Y, 2010. Spatio-temporal coupling relationship between farmland and agricultural labor changes at county level in China. Acta Geographica Sinica, 65(12): 1602-1612. (in Chinese)

Liu Y, Shen J, 2013. Jobs or amenities? Location choices of interprovincial skilled migrants in China, 2000-2005. Population, Space and Place. doi: 10.1002/psp.1803.

Liu Y, Stillwell J, Shen J et al., 2014a. Interprovincial migration, regional development and state policy in China, 1985-2010. Applied Spatial Analysis and Policy, 7(1): 47-70.

Liu J, Su Y, Wei F, 2013. Research on population scale regulation of megacities based on the regional population carrying capacity. China Soft Science, (10): 147-156. (in Chinese)

Liu Y, Sui Z, Kang C et al., 2014b. Uncovering patterns of inter-urban trip and spatial interaction from social media check-in data. PloS One, 9(1): e86026.

Liu Y, Xu W, 2017. Destination choices of permanent and temporary migrants in China, 1985-2005. Population, Space and Place, 23: e1963.

Lu D, Guo L, 1998. Man-earth areal system: The core of geographical study on the geographical thoughts and academic contributions of Academician Wu Chuanjun. Acta Geographica Sinica, 53(2): 3-11. (in Chinese)

Luo Y, Wang D, Liu J et al., 2013. Should population in megacities be regulated mainly by administrative meas- 
ures: Based on the regional population carrying capacity. Population and Economics, (1): 52-60. (in Chinese)

$\mathrm{Ma}$ H, 2015. China's new urbanization plan is a breakthrough against Hu Huanyong Line. Science, 67(3): 39-42. (in Chinese)

Ma Y, 1957. The New Population Theory. Beijing: People's Daily, 1957-07-05. (in Chinese)

National Bureau of Statistics of China (NBSC), 2014. China Statistical Yearbook. Beijing: China Statistics Press, 937. (in Chinese)

National Research Council (NRC), 2010. Understanding the Changing Planet: Strategic Directions for Geographical Sciences. Washington, DC: National Academies Press, 172.

Pan Q, Jin X, Zhou Y, 2013. Population change and spatiotemporal distribution of China in recent 300 years. Geographical Research, 32(7): 1291-1302. (in Chinese)

Park R E, Burgess E W, 1921. Introduction to the Science of Sociology. Chicago: University of Chicago Press, 902.

Qi W, Liu S, Zhao M, 2015. Study on the stability of Hu Line and different spatial patterns of population growth on its both sides. Acta Geographica Sinica, 70(4): 551-566. (in Chinese)

Qiao X, 2014a. How high would be the fertility level if implementing "Two-child Policy"? Discussion with Prof. Zhai Zhen-wu. Population and Development, 20(6): 2-15. (in Chinese)

Qiao X, 2014b. What will be the consequences of the implementation of "Single two-child policy"? Findings based on the survey of fertility intention in 2013. Population and Family Planning, (3): 18-22. (in Chinese)

Qiao X, 2015. The choice of coming fertility policy through the effect of the new policy. Chinese Journal of Population Science, (2): 26-33. (in Chinese)

Ratzel F, 1882. Anthropo-geographie. Stuttgart, Germany: J. Engelhorn, 526.

Ratzel F, 1891. Anthropo-geographie. Stuttgart, Germany: J. Engelhorn.

Russell H, 2003. Human carrying capacity is determined by food availability. Population and Environment, 25(2): 109-117.

Shi Y, Yin C, Wang H et al., 2013. Research progress and prospect on urban comprehensive carrying capacity. Geographical Research, 32(1): 133-145. (in Chinese)

Silverman S J, Massa E, 2012. Why immigration detention is unique. Population, Space and Place, 18(6): $677-686$.

Smith D P, King R, 2012. Editorial introduction: Remaking migration theory. Population, Space and Place, 18(2): $127-133$.

Tong Y, 2010. Dynamic simulation and analysis to population carrying capacity of Beijing. China Population, Resources and Environment, 20(9): 42-47. (in Chinese)

Tong Y, 2012. Research on population carrying capacity: Evolution, problems and prospect. Population Research, 36(5): 28-36. (in Chinese)

Trewartha G T, 1953. A case for population geography. Annals of the Association of American Geographers, 43(2): 71-97.

Tyner J A, 2014. Population geography II: Mortality, premature death, and the ordering of life. Progress in Human Geography, 39: 360-373.

UNESCO, FAO, 1985. Carrying capacity assessment with a pilot study of Kenya: A resource accounting methodology for sustainable development. Paris and Rome: UNESCO/FAO.

Vogt W, Baruch B M, 1948. Road to Survival. Whitefish, Montana: Kessinger Publishing, 356.

Wang D, Chen S, Gao Q et al., 2011. Approach to spatial differences analysis of urban carrying capacity: A case study of Changzhou City. Acta Ecologica Sinica, 31(5): 1419-1429. (in Chinese)

Wang G, 1998. Geographical distribution and its change of China's population. Population Research, 22(6): 41-46. (in Chinese)

Wang G, 2015. Rethinking the problems in the research of China's family planning policy adjustment. Chinese Journal of Population Science, (2): 2-15. (in Chinese)

Wang G, Chen G, 2010. China's population changes and economic growth. Population Journal, (3): 3-9. (in Chinese)

Wang G, Pan Z, Lu Y, 2012a. China's inter-provincial migration patterns and influential factors: Evidence from year 2000 and 2010 population census of China. Chinese Journal of Population Science, (5): 2-13. (in Chinese)

Wang G, Qin Z, Cheng Y, 2012b. Spatial distribution of population migration in China in the 1990s: A perspective of city. Scientia Geographica Sinica, 32(3): 273-281. (in Chinese) 
Wang G, Zhang L, 2012. How many births can we have? The potential birth estimation under policy. Sociological Studies, (5): 119-140.

Wang L, Feng Z, Yang Y, 2015. The change in population density from 2000 to 2010 and its influencing factors in China at the county scale. Journal of Geographical Sciences, 25(4): 485-496. (in Chinese)

Wang L, Yang Y, Feng Z et al., 2014. Prediction of China's population in 2020 and 2030 on county scale. Geographical Research, 33(2): 310-322. (in Chinese)

Wang Q, Tang L, Li H, 2015. Return Migration of the Highly Skilled in Higher Education Institutions: a Chinese University Case. Population, Space and Place, 21(8):771-787.

Wang Y, 1998. Population carrying capacity of mineral resources. China Population, Resources and Environment, 8(3): 19-22. (in Chinese)

Wang Y, Liu Y, Li Y et al., 2016. The spatio-temporal patterns of urban-rural development transformation in China since 1990. Habitat International, 53: 178-187.

Weng W, 1932. The distribution of population and land utilization in China. Independent Review, 3(4): 9-12. (in Chinese)

Willmott C J, 1989. Geography in America. Columbus, Ohio: Merrill Publishing Company, 848.

Woods R, 1979. Population Analysis in Geography. London: Longman.

Wu J, Wang Z, 2008. Agent-based simulation on the evolution of population geography of China during the past 2000 years. Acta Geographica Sinica, 63(2): 185-194. (in Chinese)

Wu X, Zhang Z, 2015. Population migration and children's school enrollments in China, 1990-2005. Social Science Research, 53: 177-190.

Xiang B, 2007. How far are the left-behind left behind? A preliminary study in rural China. Population, Space and Place, 13(3): 179-191.

Yang Y, 1993. Latitudinal and longitudinal distribution of China's population and the dynamic analysis of population central points. Population Research, (2): 28-33. (in Chinese)

Yao Y, Li F, Yin W, 2014. Accumulated couples and fertility release under the new fertility policy. Population Research, 38(4): 3-18. (in Chinese)

Yeoh B S, Huang S, 2010. Sexualised politics of proximities among female transnational migrants in Singapore. Population, Space and Place, 16(1): 37-49.

Yin W, Yao Y, Li F, 2014. Evaluation of fertility levels and adjustment of fertility policy: Based on the current situation of the Chinese Mainland's provincial fertility levels. Social Sciences in China, 35(2): 83-105. (in Chinese)

Zhai Z, Zhang X, Jin Y, 2014. Demographic consequences of an immediate transition to a universal two-child policy. Population Research, 38(2): 3-17. (in Chinese)

Zhang K H, Song S, 2003. Rural-urban migration and urbanization in China: Evidence from time-series and cross-section analyses. China Economic Review, 14(4): 386-400.

Zhang S, 2002. Changes in regional distribution of Chinese population during 1959-1961. Chinese Journal of Population Science, (3): 67-72. (in Chinese)

Zhang S, 2006. Introduction to Population Geography. Shanghai: East China Normal University Press, 466. (in Chinese)

Zhang Y, 1934. The seriousness of the population problem in China. Acta Geographica Sinica, 1(1): 1-17. (in Chinese)

Zhang Y, Song Y, Zhang C, 2015. The new urbanization and the possibility of breaking through the "Hu Line." Journal of East China Normal University (Philosophy and Social Sciences), (2): 101-112.

Zhao Y, Wang S, 2015. The relationship between urbanization, economic growth and energy consumption in China: An econometric perspective analysis. Sustainability, 7(5): 5609-5627. (in Chinese)

Zheng X, Luo Y, Zhao T et al., 2012. Geographical and climatological characterization of aerosol distribution in China. Scientia Geographica Sinica, 32(3): 265-272. (in Chinese)

Zhu C, Sun S, Li Z, 2008. The influencing factors and spatial distribution of population urbanization in China. Geographical Research, 27(1): 13-22. (in Chinese)

Zhu K, 1926. The population density of Jiangsu and Zhejiang. Eastern Miscellany, 23(1): 13-18. (in Chinese)

Zuo X, 2012. A prospect for Chinese population in the 21 st century. Journal of Peking University (Philosophy and Social Sciences), 49(5): 100-106. (in Chinese) 